\title{
A atuaçáo do terapeuta ocupacional em Unidade de Terapia Intensiva: uma revisão sistemática
}

\section{The role of the occupational therapist in the Intensive Care Unit: a systematic review}

Estéfanny da Silva Bittencourt ${ }^{a}$ (D), Paula Silva Moreira ${ }^{a}$ (D), Glenda Miranda da Paixão ${ }^{a}$ (D), Marcelo Marques Cardoso ${ }^{a}$

${ }^{a}$ Universidade Federal do Pará - UFPA, Belém, PA, Brasil.

Como citar: Bittencourt, E. S., Moreira, P. S., Paixão, G. M., \& Cardoso, M. M. (2021). A atuação do terapeuta ocupacional em Unidade de Terapia Intensiva: uma revisão sistemática. Cadernos Brasileiros de Terapia Ocupacional, 29, e2800. https://doi.org/10.1590/2526-8910.ctoAR2118

\begin{abstract}
$\underline{\text { Resumo }}$
Introduçáo: A participação do terapeuta ocupacional (TO) em Unidades de Terapia Intensiva (UTI) ainda é discreta no Brasil, talvez, por isso, haja pouca discussão das intervençôes e inserção do profissional nessa área. Objetivo: Sintetizar as atuaçôes do TO para restabelecimento da função em pacientes adultos internados na UTI mais frequentemente descritas na literatura especializada. Método: Revisão Sistemática baseada na recomendação PRISMA. A busca dos estudos foi realizada nas plataformas Cochrane, PubMed, OTSeek e PEDro, utilizando os termos de busca "Occupational Therapy", no título ou resumo, $(A N D)$ "Intensive Care Unit" $(O R)$ "Critical Illness" (OR) "Critical Care", em outras partes do texto. Foram incluídos textos em língua inglesa e publicados nos últimos 20 anos. Excluiu-se textos que abordavam UTI pediátrica/neonatal, doenças psiquiátricas e artigos de revisão. Dois pesquisadores independentes selecionaram os artigos e a concordância foi submetida à análise Kappa. O nível de evidência e a qualidade metodológica dos estudos incluídos foram avaliados pela Escala PEDro e pela Ferramenta de Colaboração Cochrane, respectivamente. Resultados: As principais intervençôes foram relativas ao treino de Atividades de Vida Diária (AVDs) e tarefas relacionadas às Atividades Instrumentais de Vida Diária (AIVDs). Essas atribuiçốes privativas da profissão ocorreram isoladamente ou com fisioterapeutas. As sessôes, excluídos os critérios de contraindicaçáo, aconteceram precocemente (24-48h). Conclusáo: Os achados evidenciam intervenções de mobilização precoce, seguidas por práticas de treino de AVDs/ AIVDs. Ademais, é notado que a atuação do terapeuta ocupacional na UTI está em elaboração. Estudos sobre outros efeitos da internação prolongada na UTI devem ser conduzidos. Registro PROSPERO: CRD42020214615.
\end{abstract}


Palavras-chave: UTI, Hospitais, Terapia Ocupacional, Atividades Cotidianas, Reabilitação.

\section{$\underline{\text { Abstract }}$}

Introduction: The participation of the occupational therapist (OT) in Intensive Care Units (ICU) is still discreet in Brazil, perhaps because of this, there is a little discussion of interventions and insertion of this professional in this area. Objective: To synthesize the actions of OT to restore function in adult patients admitted to the ICU most frequently described in the specialized literature. Method: Systematic review based on the PRISMA recommendation. The search for the studies was carried out on the Cochrane, PubMed, OTSeek, and PEDro platforms using the search terms "Occupational Therapy", in the title or abstract, (AND) "Intensive Care Unit" (OR) "Critical Illness" (OR) "Critical Care", in other parts of the text. English-language texts published in the last 20 years were included and texts that describe interventions in pediatric/neonatal ICU, psychiatric diseases, and review articles were excluded. Two independent researchers selected the articles and the agreement was submitted to Kappa analysis. The level of evidence and methodological quality of the included studies were assessed using the PEDro Scale and the Cochrane Collaboration Tool, respectively. Results: The main interventions were related to the training of Activities of Daily Living (ADLs) and tasks related to Instrumental Activities of Daily Living (IADLs). These private attributions of the profession occurred isolated or with physiotherapists. The sessions, excluding the contraindication criteria, took place early (24-48h). Conclusion: The findings show early mobilization interventions, followed by ADLs/IADLs training and it is also noted that the work of the occupational therapist in the ICU is under development. Studies on other effects of prolonged ICU stay should be conducted. PROSPERO record: CRD42020214615.

Keywords: Intensive Care Units, Hospitals, Occupational Therapy, Activities of Daily Living, Rehabilitation.

\section{Introduçáo}

A Unidade de Terapia Intensiva (UTI) configura um ambiente singular dentro do hospital, por ser uma área destinada à internação de pacientes que requerem atenção profissional especializada de forma contínua, materiais específicos e tecnologias necessárias ao monitoramento e ao tratamento. A UTI é destinada ao tratamento do paciente grave, definido como aquele com comprometimento de um ou mais dos principais sistemas fisiológicos, com perda da autorregulaçáo, devendo atender a pelo menos um dos seguintes critérios na avaliação médica: 1) requer pelo menos 12 horas de cuidados de enfermagem; 2) requer monitorizaçáo hemodinâmica invasiva; 3) requer monitoramento da pressão intracraniana; 4) requer ventilaçáo mecânica (Brasil, 2010; Affleck et al., 1986). Ressalta-se que pacientes em ventilação mecânica devem estar sob sedação e analgesia para tolerar a entubação e manter o posicionamento no leito, evitar dissincronia com o ventilador e otimizar a oxigenação (Gurudatt, 2011). Devido a essas características, a internação prolongada na UTI pode ocasionar problemas físicos; entre eles, os mais frequentemente observados, mesmo após poucos dias de internação, são a fraqueza adquirida (Wieske et al., 2015) e a atrofia muscular (Koukourikos et al., 2014), e, dentre os problemas cognitivos, destaca-se o delirium como o mais frequente (Álvarez et al., 2017). A permanência 
prolongada nessas condiçóes favorece o surgimento de um conjunto de sintomas que integram a Síndrome Pós-Cuidados Intensivos (PICS - Post Intensive Care Syndrome), entre os quais sobressaem os prejuízos físicos e funcionais, cognitivos e psicoemocionais (Held \& Moss, 2019).

Portanto, os cuidados demandados por pacientes graves sob suporte ventilatório mecânico, sedação e mobilidade restrita reforçam a necessidade de formação qualificada e de conhecimento prévio diferenciado para atuação na UTI (Thomas et al., 2017). A especialidade, qualidade e a multidisciplinaridade dos serviços trazem benefícios, como a redução do tempo de permanência na UTI e a duração da internação hospitalar (Wu et al., 2019). Nesse cenário, observa-se a intervenção do terapeuta ocupacional, individualizada (Dinglas et al., 2013), como membro da mobilizaçáo precoce/reabilitaçáo (Ratcliffe \& Williams, 2019), ou membro da equipe multidisciplinar (Hsu et al., 2020).

Sobre a atividade do terapeuta ocupacional com pacientes na UTI, a literatura especializada da área aponta atuaçóes que culminam no autocuidado, abordagens cognitivas, dispositivos de adaptação e posicionamento no leito, estendendo-se à mobilização precoce (ProvanchaRomeo et al., 2019). Deste último, um recente levantamento de intervençóes de terapeutas ocupacionais na UTI caracterizou as atuaçóes relacionadas à mobilização precoce como as mais demandadas, seguida de intervençóes cognitivas e ambientação (Costigan et al., 2019). Contudo, ainda não é claro quais são as atividades, tarefas ou os recursos que integram essas formas de intervenções do profissional. Agrava essa situação a percepção da reduzida participação de terapeutas ocupacionais com pacientes graves na UTI, mesmo com o acervo literário crescente e o amparo normativo específico da Agência de Vigilância Sanitária desde 2010 (Brasil, 2010), que garante a participaçáo do terapeuta ocupacional na equipe da UTI (Bombarda et al., 2016). Por essa constatação, torna-se importante a identificação, a classificação e a exposição de atribuiçóes privativas ou náo desse profissional, as quais o integre decisivamente nos atendimentos aos pacientes na UTI.

Dessa forma, a originalidade deste trabalho está na discriminação e na descrição das atuações de terapeutas ocupacionais na UTI, os achados tendem a ser importantes, particularmente, aos profissionais que estão sendo inseridos nessa área hospitalar e às instituiçôes hospitalares que ainda não possuem um conjunto de procedimentos debatidos com a equipe para inserçáo de rotinas inerentes ao terapeuta ocupacional. Assim, objetiva-se sintetizar as atuações terapêuticas ocupacionais mais recorrentes sobre a funcionalidade de pacientes internados em UTI, nas últimas duas décadas, e ressaltar os parâmetros de indicação para o início do serviço e de sinais vitais de controle que garantem a manutenção da sessão.

\section{Método}

Este estudo é uma revisão sistemática elaborada de acordo com as diretrizes do Preferred Reporting Items for Systematic Reviews and Meta-analyses - PRISMA (Moher et al., 2015) e registrada no International Prospective Register of Systematic Reviews (PROSPERO), pela codificação CRD42020214615.

\section{Estratégias de busca e critérios de seleção}

Nos meses de janeiro a maio de 2020, pelo menos dois pesquisadores independentes realizaram buscas nas seguintes bases de dados eletrônicas: Cochrane Library, Occupational Therapy Systematic Evaluation of Evidence (OTSeeker), Physiotherapy Evidence Database 
(PEDro) e PubMed (National Centerfor Biotechnology Information). Foram utilizados descritores em língua inglesa, obtidos com base no Medical Subject Headings (MeSH), com a seguinte combinação: "Occupational Therapy" AND "Intensive Care Units" OR "Critical Illness" OR "Critical Care”. O detalhamento é apresentado na Tabela 1.

Tabela 1. Esquema da estratégia de busca: Descritores, filtro e operadores booleanos.

\begin{tabular}{|c|c|c|c|c|c|c|}
\hline Plataformas & $\begin{array}{l}\text { Descritor/ } \\
\text { Filtro }\end{array}$ & Booleanos & $\begin{array}{l}\text { Descritor/ } \\
\text { Booleanos }\end{array}$ & Filtro & $\begin{array}{r}\text { Quantid } \\
\text { Artig }\end{array}$ & $\begin{array}{l}\text { de de } \\
\text { s }\end{array}$ \\
\hline Cochrane & \multirow{4}{*}{$\begin{array}{c}\text { Occupational } \\
\text { Therapy } \\
\text { (Abstractl Title) }\end{array}$} & \multirow{4}{*}{$A N D$} & \multirow{4}{*}{$\begin{array}{c}\text { Intensive Care } \\
\text { Units } \\
\text { OR } \\
\text { Critical Illness } \\
\text { OR } \\
\text { Critical Care }\end{array}$} & All Fields & 273 & \multirow{4}{*}{618} \\
\hline OTSeeker & & & & All Fields & 13 & \\
\hline PEDro & & & & $\begin{array}{c}\text { Abstractl } \\
\text { Title }\end{array}$ & 22 & \\
\hline PubMed & & & & All Fields & 310 & \\
\hline
\end{tabular}

Foram incluídos na pesquisa estudos em língua inglesa, publicados entre janeiro de 2001 e maio de 2020, que descrevessem a atuação de terapeutas ocupacionais em UTI adulto, individualmente ou em equipe multidisciplinar. Estudos duplicados, em idiomas diferentes da língua inglesa, ou que abordassem atuação em UTI pediátrica/neonatal, casos de doenças psiquiátricas (alteraçóes de humor e ansiedade), assim como qualquer categoria de artigo de revisão foram excluídos. A Figura 1 resume o fluxo de busca.

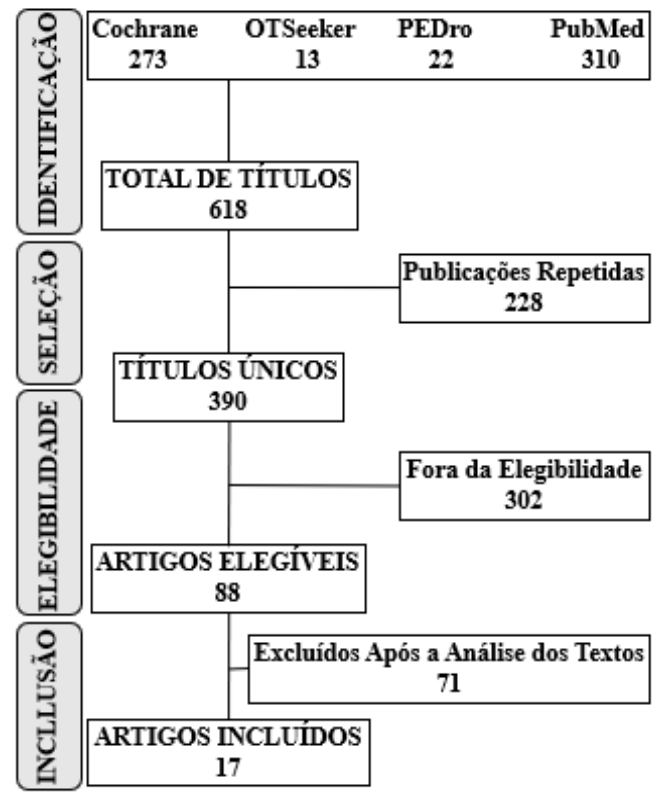

Figura 1. Fluxograma PRISMA: Identificação dos artigos nas bases de dados e inclusão no estudo. 


\section{Extração e análise dos dados}

Pelo menos dois dos pesquisadores que realizaram as buscas na literatura também extraíram independentemente os dados dos estudos incluídos. As discordâncias foram resolvidas por um terceiro pesquisador. Foram extraídas as seguintes variáveis: autoria/ano, objetivo, tipo de UTI, desenho do estudo, amostra, presença ou ausência de ventilação mecânica, tempo/período de início da intervenção, contraindicações à intervenção, sinais vitais monitorados durante a sessão, atuação do terapeuta ocupacional individualizada ou em associação com os demais profissionais da equipe/reabilitação, atuaçóes do terapeuta ocupacional na UTI e principal resultado.

A análise dos artigos incluídos e as inferências dos resultados foram realizadas quanto à avaliaçáo da qualidade metodológica dos artigos, à ponderação do nível de evidência e ao grau de confiabilidade e concordância entre os pesquisadores.

A Ferramenta de Colaboração Cochrane (Higgins et al., 2019a) foi usada para identificar a qualidade metodológica dos artigos incluídos, pela análise do risco de viés, quanto à(ao): geraçáo de sequência, ocultação de alocação, mascaramento, dados de resultados incompletos e resultados seletivos. Esses domínios foram usados para ponderar a qualidade das publicaçóes em: alto, baixo ou incerto (Tabela 1), segundo instruçóes de Carvalho et al. (2013).

A Escala PEDro foi aplicada para analisar o nível de evidência dos artigos incluídos. Trata-se de um instrumento com 11 itens de pontuação binária: 1 (um) para a presença ou 0 (zero) para a ausência do item em levantamento. O primeiro item da escala não é pontuado e os subsequentes o são (itens de 2 a 11) apenas se estiverem claro e satisfatoriamente identificados no manuscrito; assim, a pontuação final varia de 0 (zero) a 10 (dez) (Shiwa et al., 2011). Usualmente, a Escala PEDro qualifica estudos controlados aleatórios e, nesta revisão, foi aplicada também às variaçóes: estudos de Coorte, Transversal, (Pros/Retros)pectivo e Piloto, semelhante ao já realizado na literatura (Zago et al., 2018; Paz et al., 2016).

Para apurar o grau de concordância entre os pesquisadores na seleção dos artigos com base nos critérios de elegibilidade, foi utilizada a Análise Kappa (k). A definição do grau de confiabilidade entre os pesquisadores no cálculo do nível de evidência das publicações incluídas foi estabelecida pelo Índice de Correlação Intraclasse (ICC). A magnitude k ou ICC foi interpretada como: Ausente (0); Pobre $(0-0,19)$; Fraca $(0,20-0,39)$; Moderada (0,40 - 0,59); Substancial (0,60 - 0,79); e Quase Perfeita ( $\geq 0,80)$ (Higgins et al., 2019b; Ohura et al., 2017; Miot, 2016). Os dados foram analisados no Programa SPSS (IBM", versão 20) e a significância estatística foi estabelecida para valores de $\mathrm{p}<0,05$.

\section{Resultados}

No resultado das pesquisas nas plataformas eletrônicas de buscas foram encontrados 618 artigos, dos quais 390 títulos não eram repetidos. Isso caracteriza incipiência das publicações sobre $\mathrm{o}$ assunto frente à janela temporal de busca. Por outro lado, foram incluídos 17 artigos, publicados entre 2001 e 2020, denotando a importante atualidade das informaçóes. A seleção dos títulos e a inclusão dos artigos alcançou o grau de concordância entre os pesquisadores de classificaçáo quase perfeita $(\mathrm{k}=0,895, \mathrm{p}<0,001)$. Trata-se de um índice de valor relevante, cuja diferença para o patamar de excelência foi prejudicada pela dificuldade de se identificar atuaçóes do terapeuta ocupacional em publicaçóes ou de se discriminar nelas intervençóes da profissão. Uma vez 
incluídos, os artigos tiveram o nível de evidência analisado. Essa ponderação alcançou a correlação intraclasse de magnitude também quase perfeita ( $I C C=0,874, \mathrm{IC}_{95 \%}$ : 0,656 a 0,954-p<0,001).

A avaliação metodológica, pelo risco de viés, evidencia que, dos artigos incluídos, os domínios de maiores incertezas foram a geração de sequência de randomização (15/17), mascaramento na avaliaçáo de desfecho (14/17) e o mascaramento de participantes e equipe (13/17). Os domínios com os riscos mais baixos e maiores frequências foram os dados incompletos de desfechos (9/17) e o relato seletivo de desfechos (7/17). Por fim, o mais alto risco de viés e maior repetição foi referente ao sigilo da alocação (8/17). A visualização geral desses dados possibilita a interpretação de que a maioria dos artigos incluídos apresentam classificação baixa ou incerta quanto ao risco de viés (Tabela 2).

Tabela 2. Análise do Risco de Viés: Avaliação pela Ferramenta Colaborativa da Cochrane.

\begin{tabular}{|c|c|c|c|c|c|c|c|}
\hline \multirow[b]{2}{*}{ Estudos } & \multicolumn{7}{|c|}{ Risco de viés } \\
\hline & 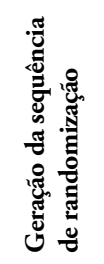 & 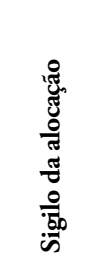 & 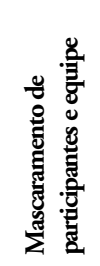 & 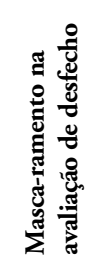 & 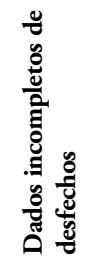 & 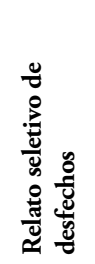 & 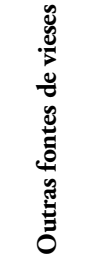 \\
\hline Brummel et al. (2014) & Baixo & Baixo & Alto & Alto & Baixo & Baixo & Incerto \\
\hline Corcoran et al. (2017) & Incerto & Alto & Alto & Alto & Incerto & Baixo & Incerto \\
\hline Davis et al. (2013) & Incerto & Alto & Incerto & Incerto & Incerto & Baixo & Incerto \\
\hline Deluzio et al. (2018) & Incerto & Alto & Incerto & Incerto & Incerto & Incerto & Incerto \\
\hline Fields et al. (2015) & Incerto & Alto & Incerto & Incerto & Baixo & Incerto & Incerto \\
\hline Hsu et al. (2020) & Incerto & Incerto & Incerto & Incerto & Baixo & Incerto & Incerto \\
\hline Jolley et al. (2015) & Incerto & Incerto & Incerto & Incerto & Baixo & Incerto & Incerto \\
\hline Jolley et al. (2017) & Incerto & Incerto & Incerto & Incerto & Baixo & Incerto & Incerto \\
\hline Needham et al. (2010) & Incerto & Alto & Alto & Incerto & Incerto & Incerto & Incerto \\
\hline Pohlman et al. (2010) & Incerto & Incerto & Incerto & Incerto & Incerto & Incerto & Incerto \\
\hline Schweickert et al. (2009) & Baixo & Baixo & Alto & Alto & Baixo & Baixo & Incerto \\
\hline Sigler et al. (2016) & Incerto & Incerto & Incerto & Incerto & Incerto & Incerto & Incerto \\
\hline Titsworth et al. (2012) & Incerto & Alto & Incerto & Incerto & Baixo & Incerto & Incerto \\
\hline Wahab et al. (2016) & Incerto & Alto & Incerto & Incerto & Baixo & Incerto & Incerto \\
\hline Witcher et al. (2015) & Incerto & Alto & Incerto & Incerto & Baixo & Baixo & Incerto \\
\hline Yataco et al. (2019) & Incerto & Incerto & Incerto & Incerto & Baixo & Baixo & Incerto \\
\hline Zanni et al. (2010) & Incerto & Incerto & Incerto & Incerto & Incerto & Baixo & Incerto \\
\hline
\end{tabular}

Após a consolidação das buscas, constatou-se que cinco artigos (29,4\%) descrevem especificamente intervençóes de terapeutas ocupacionais em UTIs, enquanto 12 artigos (70,6\%) descrevem práticas de reabilitaçáo física precoce, citando o profissional terapeuta ocupacional. Disso, infere-se que as atuaçóes do terapeuta ocupacional estão associadas à equipe multiprofissional/reabilitaçáo da UTI; ou à possibilidade de a profissão necessitar de mais escopo científico e habilidades técnicas para prover atuaçôes independentes (Tabela 3). 
Tabela 3. Apresentaçâo científica. Ficha técnica geral dos artigos incluídos.

\begin{tabular}{|c|c|c|c|c|c|}
\hline \multirow[t]{2}{*}{ Autoria/Ano. } & \multirow[t]{2}{*}{ Objetivo. } & \multirow[t]{2}{*}{$\begin{array}{l}\text { Desenho do } \\
\text { Estudo. }\end{array}$} & $\begin{array}{c}\text { (1) Diferencia atuaçóes do } \\
\text { terapeuta ocupacional de } \\
\text { outras profissóes. } \\
\end{array}$ & \multirow[t]{2}{*}{$\begin{array}{l}\text { Principais } \\
\text { Resultados. }\end{array}$} & \multirow[t]{2}{*}{ Escala PEDro. } \\
\hline & & & (2) Outras atribuiçóes. & & \\
\hline \multirow[b]{2}{*}{ Brummel et al. (2014) } & \multirow[b]{2}{*}{$\begin{array}{c}\text { Uso precoce e } \\
\text { combinado de terapia } \\
\text { cognitiva. }\end{array}$} & \multirow[b]{2}{*}{ Randomizado. } & (1) Sim. & \multirow[b]{2}{*}{$\begin{array}{l}\text { Viável e seguro, mesmo sob } \\
\text { ventilação mecânica. }\end{array}$} & \multirow[b]{2}{*}{$7 / 10$} \\
\hline & & & $\begin{array}{l}\text { (2) Terapia Cognitiva (Re- } \\
\text { solver problemas; execuçáo } \\
\text { de tarefas em multi-etapas). }\end{array}$ & & \\
\hline \multirow[b]{2}{*}{ Corcoran et al. (2017) } & \multirow[b]{2}{*}{$\begin{array}{l}\text { Mobilização precoce na } \\
\text { UTI. }\end{array}$} & \multirow[b]{2}{*}{ Prospectivo. } & (1) Não. & \multirow{2}{*}{$\begin{array}{l}\text { Viável com redução da } \\
\text { hospitalizaçâo e de } \\
\text { permanência nas UTIs. }\end{array}$} & \multirow[b]{2}{*}{$5 / 10$} \\
\hline & & & $\begin{array}{l}\text { (2) Exercícios no leito; Ficar } \\
\text { em pé; Deambulaçáo. }\end{array}$ & & \\
\hline \multirow[b]{2}{*}{ Davis et al. (2013) } & \multirow[b]{2}{*}{$\begin{array}{l}\text { Viabilidade da mobi- } \\
\text { lizaçáo precoce na UTI e } \\
\text { funcionalidade sob } \\
\text { ventilaçáo mecânica. }\end{array}$} & \multirow[b]{2}{*}{ Coorte. } & (1) Não. & \multirow[b]{2}{*}{$\begin{array}{l}\text { Viável, segura e bem } \\
\text { tolerada sob ventilaçáo } \\
\text { mecânica. }\end{array}$} & \multirow[b]{2}{*}{$5 / 10$} \\
\hline & & & $\begin{array}{l}\text { (2) Mudança de decúbito, } \\
\text { sentar-se no leito e na borda } \\
\text { do leito; Ficar em pé; Sentar- } \\
\text { se na cadeira; Caminhadas. }\end{array}$ & & \\
\hline \multirow[b]{2}{*}{ Deluzio et al. (2018) } & \multirow{2}{*}{$\begin{array}{c}\text { Viabilidade do } \\
\text { Cicloergômetro em } \\
\text { pacientes neurológicos } \\
\text { críticos. }\end{array}$} & \multirow[b]{2}{*}{ Coorte. } & (1) Sim. & \multirow[b]{2}{*}{$\begin{array}{l}\text { Viável, seguro e não traz } \\
\text { mudanças fisiológicas, } \\
\text { neurológicas ou cognitivas. }\end{array}$} & \multirow[b]{2}{*}{$4 / 10$} \\
\hline & & & (2) Descrição ausente. & & \\
\hline \multirow[b]{2}{*}{ Fields et al. (2015) } & \multirow{2}{*}{$\begin{array}{l}\text { A mobilizaçáo precoce e } \\
\text { eventos adversos } \\
\text { associados. }\end{array}$} & \multirow[b]{2}{*}{ Retrospectivo. } & (1) Sim. & \multirow[b]{2}{*}{ Seguro e eficaz. } & \multirow[b]{2}{*}{$4 / 10$} \\
\hline & & & (2) Descrição ausente. & & \\
\hline \multirow[b]{2}{*}{ Hsu et al. (2020) } & \multirow[b]{2}{*}{$\begin{array}{c}\text { Nível de recordação, } \\
\text { satisfaçáo e benefícios } \\
\text { durante a ventilaçăo } \\
\text { mecânica. }\end{array}$} & \multirow[b]{2}{*}{ Estudo Piloto. } & (1) Sim. & \multirow[b]{2}{*}{$\begin{array}{l}\text { Comprometimento da } \\
\text { memória factual. }\end{array}$} & \multirow[b]{2}{*}{$5 / 10$} \\
\hline & & & $\begin{array}{l}\text { (2) Controle postural; Rea- } \\
\text { çấo de equilibrio; ADM; } \\
\text { Sentar-se e ficar em pé; } \\
\text { Transferência para uma } \\
\text { cadeira e para o leito; } \\
\text { Deambulaçấo. }\end{array}$ & & \\
\hline & & & (1) Não. & & \\
\hline Jolley et al. (2015) & $\begin{array}{l}\text { Mobilizaçāo Precoce, } \\
\text { ventilação mecânica e } \\
\text { cuidados associados. }\end{array}$ & Transversal. & $\begin{array}{l}\text { (2) Transferência de peso no } \\
\text { leito; Ficar em pé; Camin- } \\
\text { hada; Transferência do leito } \\
\text { para uma cadeira; e } \\
\text { Deambulaçáo. }\end{array}$ & $\begin{array}{l}\text { Amplo uso da mobillzaçao } \\
\text { precoce na UTI: 95,7\% sem } \\
\text { ventilaçăo mecânica; e } \\
\text { 76,6\%, sob ventilaçáo } \\
\text { mecânica. }\end{array}$ & $5 / 10$ \\
\hline & & & (1) Não. & & \\
\hline Jolley et al. (2017) & $\begin{array}{c}\text { Prevalência de } \\
\text { mobilizaçáo nas UTIs e } \\
\text { progressāo da } \\
\text { mobilidade. }\end{array}$ & Coorte. & $\begin{array}{c}\text { (2) ADM, passiva; } \\
\text { Sentar-se no leito; Sentar-se } \\
\text { na borda do leito; } \\
\text { Ficar em pé; } \\
\text { Transferência da cadeira } \\
\text { para a posiçáo em pé; } \\
\text { Marcha no mesmo ponto; } \\
\text { Deambulaçáo. }\end{array}$ & $\begin{array}{l}\text { Prevalência: } 32 \% \text { dos pa- } \\
\text { cientes na UTI; } 16 \% \text { sob } \\
\text { ventilaçâao mecânica; e } \\
4 \% \text { fora do leito. }\end{array}$ & $5 / 10$ \\
\hline & & & (1) Não. & & \\
\hline Needham et al. (2010) & $\begin{array}{l}\text { Práticas de sedação e } \\
\text { analgesia na UTI e } \\
\text { mobilizaçáo funcional. }\end{array}$ & Retrospectivo. & $\begin{array}{l}\text { (2) Sentar-se no leito; Sen- } \\
\text { tar-se na borda do leito; } \\
\text { Transferência do leito para } \\
\text { uma cadeira; Transferência } \\
\text { de sentado para em pé; e } \\
\text { Deambular. }\end{array}$ & $\begin{array}{l}\text { A sedação profunda não foi } \\
\text { necessária e houve tolerância } \\
\text { à ventilação mecânica. } \\
\text { Viável, segura e redução da } \\
\text { hospitalização. }\end{array}$ & $5 / 10$ \\
\hline & Interrupção diária da & & (1) Não. & & \\
\hline Pohlman et al. (2010) & $\begin{array}{l}\text { sedaçáo e mobilização } \\
\text { precoce. }\end{array}$ & Retrospectivo. & $\begin{array}{l}\text { (2) ADM (passiva, assistida } \\
\text { ou ativa); Mobilidade no }\end{array}$ & $\begin{array}{l}\text { intubação (UTI). } \\
\text { ines e seguras logo apo a }\end{array}$ & $5 / 10$ \\
\hline
\end{tabular}


Tabela 3. Continuação...

\begin{tabular}{|c|c|c|c|c|c|}
\hline \multirow[t]{3}{*}{ Autoria/Ano. } & \multirow[t]{3}{*}{ Objetivo. } & \multirow[t]{3}{*}{$\begin{array}{l}\text { Desenho do } \\
\text { Estudo. }\end{array}$} & $\begin{array}{c}\text { (1) Diferencia atuaçóes do } \\
\text { terapeuta ocupacional de } \\
\text { outras profissóes. }\end{array}$ & \multirow[t]{3}{*}{$\begin{array}{l}\text { Principais } \\
\text { Resultados. }\end{array}$} & \multirow[t]{3}{*}{ Escala PEDro. } \\
\hline & & & (2) Outras atribuiçóes. & & \\
\hline & & & $\begin{array}{l}\text { leito; Sentar-se; Ficar em pé; } \\
\text { Deambulação; Equilíbrio. }\end{array}$ & & \\
\hline $\begin{array}{c}\text { Schweickert et al. } \\
\text { (2009) }\end{array}$ & $\begin{array}{l}\text { Mobilização precoce, } \\
\text { interrupçáo da sedação e } \\
\text { resultados funcionais e } \\
\text { psiquiátricos. }\end{array}$ & Randomizado. & $\begin{array}{c}\text { (1) Não. } \\
\text { (2) Movimentos (passivos, } \\
\text { assistidos e ativos); Mobi- } \\
\text { lidade no leito (transferência } \\
\text { de peso, sentar-se no leito); } \\
\text { Equilíbrio; Ficar em pé, Sen- } \\
\text { tar-se em uma cadeira; } \\
\text { Deambulaçáo. }\end{array}$ & $\begin{array}{l}\text { Segura, bem tolerada, } \\
\text { melhora o estado funcional, } \\
\text { reduz sintomas associados à } \\
\text { UTI e aumenta o desmame. }\end{array}$ & $8 / 10$ \\
\hline Sigler et al. (2016) & $\begin{array}{c}\text { Implementação de um } \\
\text { programa de } \\
\text { mobilização precoce. }\end{array}$ & Coorte. & $\begin{array}{c}\text { (1) Não. } \\
\text { (2) Transferência de peso no } \\
\text { leito; Sentar-se no leito; } \\
\text { ADM (passiva, Assistida ou } \\
\text { ativa); Sentar-se na borda do } \\
\text { leito; Ficar em pé, virar e se } \\
\text { sentar em uma cadeira; Ficar } \\
\text { de pé, poucos passos e se } \\
\text { senta em uma cadeira; } \\
\text { Deambulaçáo. }\end{array}$ & $\begin{array}{c}\text { Mobilização progressiva, } \\
\text { simples, com modificaçáo } \\
\text { do regime de analgesia e } \\
\text { sedaçáo. }\end{array}$ & $5 / 10$ \\
\hline Titsworth et al. (2012) & $\begin{array}{c}\text { Mobilização precoce na } \\
\text { unidade de terapia } \\
\text { neurointensiva. }\end{array}$ & Retrospectivo. & $\begin{array}{c}\text { (1) Não. } \\
\text { (2) Sentar-se no leito; } \\
\text { Sentar-se na borda do leito; } \\
\text { Sair do leito; Caminhar até o } \\
\text { banheiro; Sair do quarto; } \\
\text { Exercício. }\end{array}$ & $\begin{array}{l}\text { Não prejudica o estado } \\
\text { crítico do paciente e reduz a } \\
\text { permanência na UTI. }\end{array}$ & $5 / 10$ \\
\hline Wahab et al. (2016) & $\begin{array}{l}\text { Mobilizaçáo precoce na } \\
\text { UTI de hospital de longa } \\
\text { permanência. }\end{array}$ & Retrospectivo. & $\begin{array}{c}\text { (1) Sim. } \\
\text { (2) Descrição ausente. }\end{array}$ & $\begin{array}{l}\text { Redução da permanência na } \\
\text { UTI e da hospitalização. }\end{array}$ & $5 / 10$ \\
\hline Witcher et al. (2015) & $\begin{array}{l}\text { Mobilização precoce e } \\
\text { sedaçáo em pacientes } \\
\text { neurológicos na UTI. }\end{array}$ & Retrospectivo. & $\begin{array}{l}\text { (1) Não. } \\
\text { (2) ADM (passiva e ativa); } \\
\text { Sentar-se; Ficar em pé; } \\
\text { Caminhar. }\end{array}$ & $\begin{array}{l}\text { Redução da sedaçáo, } \\
\text { aumento da analgesia. Não } \\
\text { reduziu a permanência em } \\
\text { ventilaçáo mecânica nem o } \\
\text { tempo de hospitalizaçáo. }\end{array}$ & $5 / 10$ \\
\hline Yataco et al. (2019) & $\begin{array}{c}\text { Eventos adversos da } \\
\text { mobilização. }\end{array}$ & Retrospectivo. & $\begin{array}{c}\text { (1) Não. } \\
\text { (2) Transferências (de } \\
\text { deitado para sentado); } \\
\text { Sentar-se na borda do leito; } \\
\text { Ficar em pé; Sentar-se em } \\
\text { uma cadeira; Deambulação. }\end{array}$ & $\begin{array}{c}\text { Segurança, viável com baixas } \\
\text { taxas de eventos } \\
\text { adversos. }\end{array}$ & $5 / 10$ \\
\hline Zanni et al. (2010) & $\begin{array}{c}\text { Efeitos fisiológicos e } \\
\text { segurança da reabilitaçáao } \\
\text { na UTI. }\end{array}$ & Coorte. & $\begin{array}{c}\text { (1) Não. } \\
\text { (2) ADM; Força muscular; } \\
\text { Função; Posicionamento no } \\
\text { leito; Sentar-se no leito; Sen- } \\
\text { tar-se na borda do leito; } \\
\text { Transferência de sentada } \\
\text { para em pé; Deambulaçáo; } \\
\text { Atividades. }\end{array}$ & $\begin{array}{c}\text { Segura, sem alteraçóes } \\
\text { fisiológicas significativas ou } \\
\text { efeitos adversos. }\end{array}$ & $5 / 10$ \\
\hline
\end{tabular}

(1) Diferencia atuaçóes do terapeuta ocupacional de outras profissóes - Se há a diferenciação do papel do terapeuta ocupacional na UTI. (2) Outras atribuiçóes - Intervenções classificadas como não particulares do terapeuta ocupacional, mas que podem ser exercidas pelo profissional. Descriçáo ausente - Ausência de informações objetivas no texto do manuscrito. ADM - Amplitude de Movimento. 
Com relação aos objetivos dos artigos incluídos, $82 \%$ deles levantaram questóes sobre o uso da reabilitação ou mobilização precoce na UTI. Contudo, pela análise dos métodos dos 17 artigos, a contabilidade dessas práticas aumenta para 94\%. Isso evidencia a relevância de uso de atuaçóes físicas e funcionais na UTI entre os profissionais. Os resultados desses artigos destacam a viabilidade, a segurança, a ausência de aumentos significantes de eventos adversos e realça os benefícios da utilização de atividades e tarefas precoces, como: a reduçáo do tempo de ventilação mecânica, antecipaçáo de alta da UTI e menor permanência hospitalar (Tabela 3).

Para a identificação das atividades e tarefas do terapeuta ocupacional executadas na UTI, fez-se um ordenamento em: atuaçóes compartilhadas com a equipe mais frequentemente publicadas (Tabela 3); e atribuiçóes definidas como sendo de terapeutas ocupacionais pelos artigos (Tabela 4). Entre as intervençôes mais citadas e descritas, permeia a ideia de atuação colaborativa entre os membros da equipe multidisciplinar/reabilitação da UTI, a saber: movimentos passivos, assistidos e ativos de ADM; mudanças de decúbito no leito (transferência de peso); sentar-se no leito; sentar-se na borda do leito; ficar em pé (com e sem assistência); sentar-se na cadeira; e caminhar (com e sem assistência) (Tabela 3). Independentemente da forma de execução, essas intervençôes seguiram diretrizes de progressão e de complexidade da abordagem, desde a movimentação passiva às atividades e tarefas ativas.

Tabela 4. Apresentação dos metadados de atuação do terapeuta ocupacional. Descrição, caracterização e extensão de atuação do profissional na UTI.

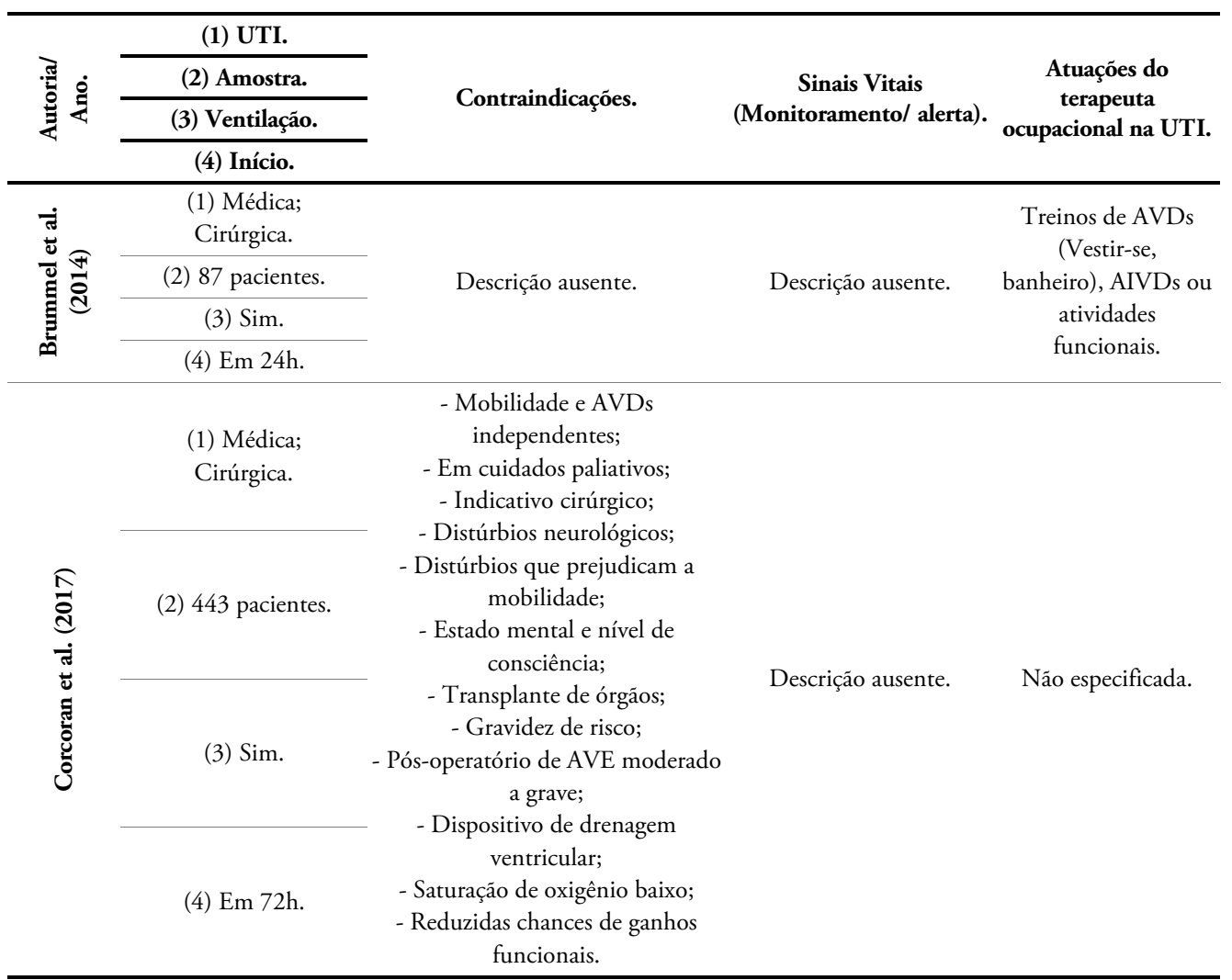


Tabela 4. Continuação...

\begin{tabular}{|c|c|c|c|c|}
\hline \multirow{4}{*}{ 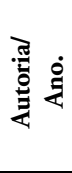 } & (1) UTI. & \multirow{4}{*}{ Contraindicaçóes. } & \multirow{4}{*}{$\begin{array}{c}\text { Sinais Vitais } \\
\text { (Monitoramento/ alerta). }\end{array}$} & \multirow{4}{*}{$\begin{array}{c}\text { Atuaçóes do } \\
\text { terapeuta } \\
\text { ocupacional na UTI. }\end{array}$} \\
\hline & (2) Amostra. & & & \\
\hline & (3) Ventilaçáo. & & & \\
\hline & (4) Início. & & & \\
\hline \multirow{11}{*}{ 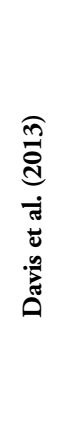 } & & \multirow{11}{*}{$\begin{array}{l}\text { - Instabilidade hemodinâmica. } \\
\text { - Distúrbio Neurológico. }\end{array}$} & - Pressão expiratória & \multirow{11}{*}{ Cita AVDs. } \\
\hline & (1) Médica; Cirúrgica. & & positiva: $>10 \mathrm{cmH}_{2} \mathrm{O}$ & \\
\hline & & & - Frequência respiratória: & \\
\hline & & & $<5$ ou $>40$ & \\
\hline & (2) 10 pacientes. & & incursôes/minuto; & \\
\hline & & & - Oximetria: $<88 \%$; & \\
\hline & (3) & & - Pressão arterial: & \\
\hline & (3) sim. & & $\begin{array}{l}<6>\text { ou }>110 \mathrm{mmHg} \text {; } \\
\text { - Frequência cardíaca: }\end{array}$ & \\
\hline & \multirow{3}{*}{ (4) em $48 \mathrm{~h}$. } & & $<40$ ou >130bpm; & \\
\hline & & & - Suspensáo de drogas & \\
\hline & & & vasoativas por $2 \mathrm{~h}$. & \\
\hline
\end{tabular}

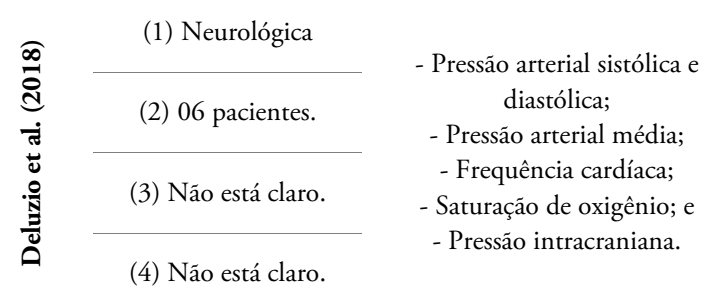

$\begin{array}{cc}\text { - Parâmetros } & \text { Modalidade de } \\ \text { hemodinâmicos; } & \text { mobilização precoce } \\ \text { - Tolerância do paciente; } & \text { não usual de } \\ \text { - Atençáo à tarefa; } & \text { terapeutas } \\ \text { - Sinais de fadiga; e } & \text { ocupacionais no } \\ \text { - Desconforto/dor. } & \text { Brasil. }\end{array}$

\begin{tabular}{|c|c|c|c|c|}
\hline \multirow{4}{*}{ 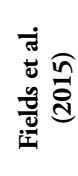 } & (1) Cardíaca. & \multirow{4}{*}{ - Instabilidade hemodinâmica. } & \multirow{4}{*}{$\begin{array}{l}\text { - Hemorragia ativa; } \\
\text { - Eventos acidentais; } \\
\text { - Arritmia cardíaca; } \\
\text { - Desconforto; e } \\
\text { - Baláo Intra-Aórtico. }\end{array}$} & \multirow{4}{*}{$\begin{array}{l}\text { Mobilidade no leito; } \\
\text { Transferências; e } \\
\text { Deambulação. }\end{array}$} \\
\hline & (2) 366 pacientes. & & & \\
\hline & (3) Náo está claro. & & & \\
\hline & (4) Não está claro. & & & \\
\hline
\end{tabular}

(1) Médica; Cirúrgica.

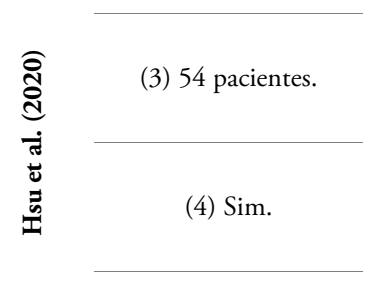

(5) Em 48h.
1) Monitoramento:

- Sinais cardiovascular e respiratórios;

- Nível de conforto; e

- Tolerância à atividade. - Pressão intracraniana elevada; - Variáveis respiratória; - Isquemia miocárdica ativa; - Instabilidade hemodinâmica;

- Hemorragia ativa; e - Abdome aberto.
2) Atenção e Proteção:

- Tubos endotraqueais, nasogástricos e/ou torácicos;

- Cateteres abdominais/ pélvicos, urinários e/ou vasculares.

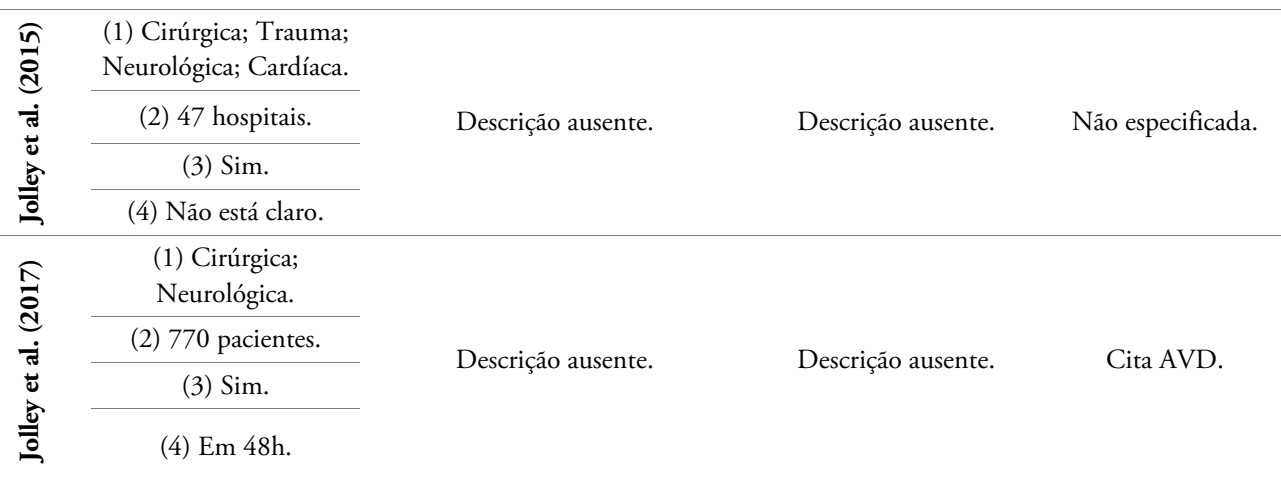


Tabela 4. Continuação...

\begin{tabular}{|c|c|c|c|c|}
\hline \multirow{4}{*}{ 焉 } & (1) UTI. & \multirow{4}{*}{ Contraindicaçóes. } & \multirow{4}{*}{$\begin{array}{c}\text { Sinais Vitais } \\
\text { (Monitoramento/ alerta). }\end{array}$} & \multirow{4}{*}{$\begin{array}{c}\text { Atuaçóes do } \\
\text { terapeuta } \\
\text { ocupacional na UTI. }\end{array}$} \\
\hline & (2) Amostra. & & & \\
\hline & (3) Ventilaçáo. & & & \\
\hline & (4) Início. & & & \\
\hline \multirow{4}{*}{ 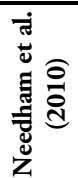 } & (1) Médica. & \multirow{4}{*}{ Descrição ausente. } & \multirow{4}{*}{ Descrição ausente. } & \multirow{4}{*}{ Não especificada. } \\
\hline & (2) 57 pacientes & & & \\
\hline & (3) Sim. & & & \\
\hline & (4) Não está claro. & & & \\
\hline
\end{tabular}

(1) Médica.

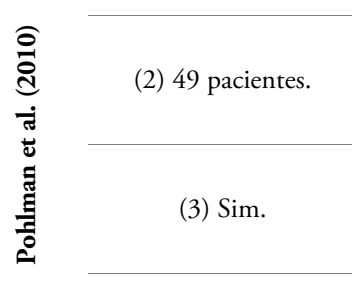

(4) Em 72h.
1) Monitoramento:

- Frequência cardíaca;

- Frequência respiratória;

- Pressáo arterial;

- Oximetria;

- Assincronia do ventilador.

- Aumenta pressão intracraniana; - Hemorragia ativa;

- Isquemia miocárdica ativa;

- Aumento de sedativo (30 minutos).

2) Atenção e Proteção:

- Cateteres de acesso vascular;

- Tubos entéricos; e

- Tubos endotraqueais.

Descreve AVDs: vestir-se,

alimentar-se, arrumar-se, banheiro e toalete.
(1) Médica.

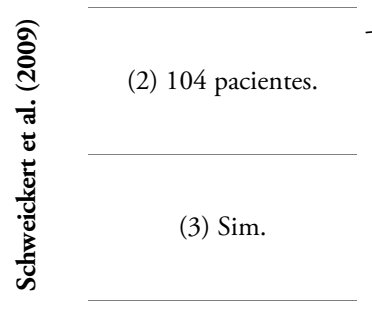

(4) $\mathrm{Em} 72 \mathrm{~h}$
- Pressáo intracraniana aumentada; - Hemorragia ativa;

- Isquemia miocárdica ativa;

- Hemodiálise intermitente; - Agitaçáo do paciente

(administração de sedativos nos últimos 30 minutos); e

- Variáveis respiratórias.

\section{1) Monitoramento:}

- Variáveis

hemodinâmicas;

-Variáveis respiratórias;

- Oximetria;

- Assincronia do

ventilador;

- Sofrimento do paciente.

Descreve AVDs:

Alimentar-se, vestir-se, arrumar-se, banheiro e toalete.

2) Atenção e Proteçấo:

- integridade dos

dispositivos das vias aéreas.

\begin{tabular}{|c|c|c|c|c|}
\hline \multirow{4}{*}{ 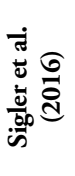 } & (1) Médica. & \multirow{4}{*}{ Descrição ausente. } & \multirow{4}{*}{ Descrição ausente. } & \multirow{4}{*}{$\begin{array}{c}\text { Descreve AVDs: } \\
\text { ir ao banheiro. }\end{array}$} \\
\hline & (2) 32 pacientes. & & & \\
\hline & (3) Sim. & & & \\
\hline & (4) Poucos dias. & & & \\
\hline \multirow{12}{*}{ 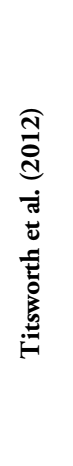 } & (1) Médica. & - Coluna vertebral instável; & \multirow{12}{*}{ Descrição ausente. } & \multirow{12}{*}{ Não especificada. } \\
\hline & (3) 170 pacientes. & - Alertas de AVE ativo; & & \\
\hline & (4) Sim. & - Ate 24 horas apos o Ativador & & \\
\hline & \multirow{9}{*}{ (5) Não está claro. } & - Intervencão endovacular. & & \\
\hline & & - Aumento da pressão & & \\
\hline & & intracraniana; & & \\
\hline & & - Ressuscitação ativa; & & \\
\hline & & - Instabilidade hemodinâmica & & \\
\hline & & - Hemodianse; & & \\
\hline & & - Cuidados agressivos de & & \\
\hline & & $\begin{array}{c}\text { ventilação; e } \\
\text { - Cuidados paliativos. }\end{array}$ & & \\
\hline & & - Cuidados paliativos. & & \\
\hline
\end{tabular}


Tabela 4. Continuação...

\begin{tabular}{|c|c|c|c|c|}
\hline \multirow{3}{*}{ 丵 } & (1) UTI. & \multirow{3}{*}{ Contraindicaçóes. } & \multirow{3}{*}{$\begin{array}{c}\text { Sinais Vitais } \\
\text { (Monitoramento/ alerta). }\end{array}$} & \multirow{3}{*}{$\begin{array}{c}\text { Atuaçóes do } \\
\text { terapeuta } \\
\text { ocupacional na UTI. }\end{array}$} \\
\hline & $\begin{array}{l}\text { (2) Amostra. } \\
\text { (3) Ventilaçáa. }\end{array}$ & & & \\
\hline & (4) Início. & & & \\
\hline \multirow{5}{*}{ 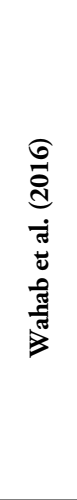 } & & \multirow{5}{*}{$\begin{array}{l}\text { - Isquemia coronária ativa; } \\
\text { - Arritmia; } \\
\text { - Tamponamento cardíaco; } \\
\text { - Variáveis respiratórias; } \\
\text { - Oximetria; } \\
\text { - Frequência cardíaca } \\
<40 \text { ou > } 130 \text { bpm; } \\
\text { - Variáveis hemodinâmicas; } \\
\text { - Glicemia < <50 mg / dL; } \\
\text { - Contraindicação ortopédica; } \\
\text { - Lesáo da medula espinhal } \\
\text { (instável); } \\
\text { - Hipertensáo intracraniana; e } \\
\text { - Obesidade mórbida. }\end{array}$} & \multirow{5}{*}{$\begin{array}{c}\text { Monitoramento: } \\
\text { - Variáveis } \\
\text { hemodinâmicas; e } \\
\text { - Dados respiratórios; e } \\
\text { - Saturaçáo de oxigênio). }\end{array}$} & \multirow{5}{*}{$\begin{array}{l}\text { Treinos de AVDs } \\
\text { (Vestir-se, } \\
\text { arrumar-se, } \\
\text { alimentar-se, } \\
\text { banheiro e toalete). }\end{array}$} \\
\hline & (1) Neurológica. & & & \\
\hline & (2) 3.945 pacientes. & & & \\
\hline & (3) Sim. & & & \\
\hline & (4) Em 24h. & & & \\
\hline \multirow{4}{*}{ 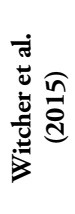 } & $\begin{array}{c}\text { (1) Médica; Cardíaca; } \\
\text { Cirúrgica. }\end{array}$ & \multirow{4}{*}{ Descrição ausente. } & \multirow{4}{*}{ Descrição ausente. } & \multirow{4}{*}{ Não especificada. } \\
\hline & (3) 68 pacientes. & & & \\
\hline & (4) Sim. & & & \\
\hline & (5) Em 24h. & & & \\
\hline \multirow{4}{*}{ 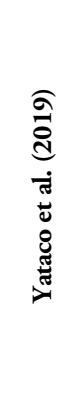 } & (1) Neurológica. & \multirow{4}{*}{$\begin{array}{c}\text { - Presença ou remoçáo de } \\
\text { introdutor arterial femoral; } \\
\text { - Variáveis hemodinâmicas; } \\
\text { - Hemorragia ativa; } \\
\text { - Angioedema; } \\
\text { - Pressão intracraniana; } \\
\text { - Neurocirurgia; } \\
\text { - Oximetria; } \\
\text { - Diaforese acentuada; } \\
\text { - Palidez facial; } \\
\text { - Hemorragia ativa. }\end{array}$} & \multirow{4}{*}{$\begin{array}{c}\text { Monitoramento: } \\
\text { - Pressão intracraniana; } \\
\text { - Pressão de perfusão } \\
\text { cerebral; } \\
\text { - Variáveis } \\
\text { hemodinâmicas; } \\
\text { - Oximetria; } \\
\text { - Dor de cabeça; } \\
\text { - Náusea; e } \\
\text { - Êmese. }\end{array}$} & \multirow{4}{*}{ Não especificada. } \\
\hline & (2) 153 pacientes. & & & \\
\hline & (3) Nấo está claro. & & & \\
\hline & (4) Avaliação diária. & & & \\
\hline \multirow{4}{*}{ 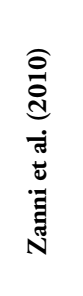 } & (1) Neurológica. & \multirow{4}{*}{ Descrição ausente. } & $\begin{array}{l}\text { 1) Monitoramento: } \\
\text { - Variáveis }\end{array}$ & \multirow{4}{*}{$\begin{array}{l}\text { Descreve AVDs: } \\
\text { (arrumar-se e } \\
\text { banheiro). }\end{array}$} \\
\hline & (2) 32 pacientes. & & $\begin{array}{l}\text { hemodinâmicas; e } \\
\text { - Oximetria. }\end{array}$ & \\
\hline & (3) Sim. & & $\begin{array}{l}\text { 2) Atenção e Proteção: } \\
\text { - Cateteres venosos e }\end{array}$ & \\
\hline & (4) Em 24 a 48h. & & $\begin{array}{c}\text { arteriais; e } \\
\text { - Tubos endotraqueais. }\end{array}$ & \\
\hline
\end{tabular}

(1) Tipo de UTI - Classificação da UTI onde o estudo foi realizado. (2) Amostra - Quantidade de pacientes participantes da pesquisa. (3) Ventilaçáo Mecânica - Se houve intervenção com pacientes durante o suporte ventilatório. (4) Início - Momento de início das sessôes de terapia ocupacional na UTI, após análise dos critérios de (contra)indicação. Náo especificada - Descrição de atribuiçôes não privativas da profissão, mas referenciadas pelos artigos incluídos como se fossem próprias do terapeuta ocupacional. Descriçáo ausente - ausência de informaçóes claras no texto do manuscrito. AVE - Acidente Vascular Encefálico.

A análise textual dos artigos incluídos possibilitou a identificação de 27 tipos de UTIs agrupados em, pelo menos, quatro categorias: Médica (40,6\%), Cirúrgica (26,0\%); Neurológica $(22,2 \%)$ e Cardiológica (11,1\%), totalizando 6.346 pacientes atendidos (Tabela 4). Durante a internação na UTI, mais de $82 \%$ das publicaçôes manifestam que os pacientes receberam suporte ventilatório mecânico, com recebimento de serviços de TO iniciados nas primeiras $24 \mathrm{~h}$ ( $40 \%$ dos 
casos) e entre $24 \mathrm{~h}$ e $48 \mathrm{~h}$ (outros $30 \%$ ), sugerindo que a maioria dos atendimentos iniciam o mais brevemente possível (Tabela 4).

Pelas atribuiçóes definidas como de natureza terapêutica ocupacional, os artigos que as discriminam representam $29,4 \%$ do total incluído, e a atuação mais citada é o treino de Atividades da Vida Diária (AVDs), seguida por tarefas funcionais extraídas de Atividades Instrumentais da Vida Diária (AIVDs) (Tabela 4). Entre essas publicações, há referências de práticas não específicas da profissão como se fossem competências do terapeuta ocupacional, com destaque a: mobilidade no leito, transferência e deambulação; e há intervençóes que fogem ao padrão brasileiro de terapia ocupacional, como uso de Cicloergômetro (Tabela 4).

Assim, a análise das publicaçóes permitiu discriminar como atividades privativas do terapeuta ocupacional em execução na UTI, o treino de AVDs e AIVDs. Dentre as AVDs, foram encontradas: alimentar-se, arrumar-se, vestir-se, autocuidar-se (higiene), (usar o) banheiro e (fazer a) toalete (Tabela 4). E dentre as AIVDs: escrita, leitura e montagem de cronograma (de tarefas) (Tabela 4). Por fim, foram encontradas outras açóes relacionadas à comunicação alternativa e dispositivos de mobilidade, aqui alocadas como atribuiçóes do escopo da profissáo (Tabela 4).

Uma vez identificadas as atuaçóes do terapeuta ocupacional na UTI, seguiu-se para os parâmetros de indicação e de contraindicação desses serviços, aliados aos sinais de alerta monitorados durante a execução das atividades, e são entendidos como requisitos para a decisão de manutenção ou de suspensão da sessão em andamento. Nem todas as publicaçóes apresentam esses tópicos. Assim, no que se refere à indicação e à contraindicação, 59\% dos artigos focam nas contraindicaçôes (Tabela 4). Disso, conseguese inferir que os limites de contraindicação são mais importantes e devem estar mais consolidados pelo terapeuta ocupacional e pela equipe no momento da avaliaçáo pelo início das sessões na UTI.

Entre os itens de contraindicação encontrados, destacam-se: variáveis hemodinâmicas (Frequência cardíaca: $<40$ ou $>130 \mathrm{bpm}$; Pressão arterial média $<55 \mathrm{mmHg}$; Pressão arterial sistólica $<90$ ou $>180 \mathrm{mmHg}$; Pressão arterial diastólica $>105 \mathrm{mmHg}$; Frequência cardíaca, em repouso, de $50 \%$ máximo ou menor que o previsto pela idade; Pressão de perfusão cerebral $<50 \mathrm{mmHg}$; e hipotensão ortostática), variáveis respiratórias (Angústia respiratória; Frequência respiratória $<5$ ou $>40$ incursôes/minuto; e Vias aéreas instáveis), saturação baixa de oxigênio ( $\mathrm{SpO} 2<88 \%$ ), pós-cirurgia (abdome aberto, incisóes, cateteres, feridas), pressão intracraniana (instável ou $>25 \mathrm{mmHg}$ ), hemorragias ativas (hemorragia gastrointestinal ativa), Lesão Medular Espinhal instável, estado mental e nível de consciência do paciente (Estado de demência moderada a grave), desconforto/dor (Expressão facial de ansiedade ou de dor) e eventos adversos (Tabela 4).

Complementarmente, dos fatores de indicação, os mais comentados, foram: parâmetros clínicos não situados na contraindicação (respiratórios, hemodinâmicos e de saturação de oxigênio), assim como os níveis de consciência e de delirium do paciente (dados não mostrados).

Vencidos os requisitos para o início das sessões de terapia ocupacional, passou-se para a identificação de situações de alerta durante a execução da sessão. Para esse fim, de 59\% dos artigos incluídos, nove pontos de monitoramento e de sinais vitais dos pacientes foram identificados, a saber: parâmetros hemodinâmicos (Frequência Cardíaca $<40$ ou $>130$ bpm; Pressão arterial média: <65 mmHg ou >110 mmHg; Pressão sistólica: >200 mmHg), 
Pressão Expiratória Positiva $\left(>10 \mathrm{cmH}_{2} \mathrm{O}\right)$, Frequência Respiratória $(<5$ ou $>40$ incursōes/minuto); Saturação Periférica de $\mathrm{O}_{2}(\mathrm{SpO} 2<88 \%)$, assincronia do ventilador, hemorragia ativa (Sangramento no local do cateter), fadiga, desconforto/dor (desconforto do paciente com o cateter), drogas vasoativas (2h) e eventos acidentais (deslocamento ou remoçáo acidental do dispositivo) (Tabela 4). Esses e outros pontos se conurbam com as contraindicaçôes e são parâmetros de acompanhamento permanente que determinam a continuidade ou a suspensão da atividade planejada.

\section{Discussão}

Primariamente, os resultados evidenciam que o terapeuta ocupacional integra a equipe de cuidados e possui participação ativa nas intervençôes com pacientes em estado crítico, principalmente na UTI Médica. Essa atuaçáo ocorre de maneira individualizada, com o escopo de atuaçóes privativas da profissão ou como membro da equipe multidisciplinar e da reabilitação/mobilização precoce. Para essas demandas, a atuação do terapeuta ocupacional mais recorrente na UTI foi o treinamento de AVDs, seguida pelas AIVDs. Outras práticas foram estabelecidas pelo profissional em parceria, principalmente, com o fisioterapeuta. Secundariamente, os parâmetros para a indicação das sessóes com o terapeuta ocupacional na UTI demonstram que o conhecimento das contraindicaçóes têm maior importância e devem estar na frente no momento da decisão pelo início do tratamento. Uma vez iniciada a sessão, o paciente deve ser permanentemente monitorado, e as alteraçóes nos sinais vitais são determinantes para a suspensão da sessão.

No contexto da UTI, artigos incluídos relatam a possibilidade de início do tratamento com a mobilização, uma opção com práticas progressivas, desde atividades passivas e assistidas até alcançar tarefas ativas (Hsu et al., 2020; Jolley et al., 2017; Sigler et al., 2016; Wahab et al., 2016; Witcher et al., 2015; Brummel et al., 2014; Pohlman et al., 2010; Schweickert et al., 2009). Esse achado tem consistência na literatura nacional, na qual as mobilizaçóes articulares e o posicionamento no leito são utilizados na UTI como precedentes às intervençóes que objetivam a funcionalidade, como o treinamento de AVDs (Bombarda et al., 2016).

A progressão de complexidade também é frequente nos treinos de AVDs, entre os quais estáo o ato de se alimentar, vestir-se, banhar-se, banheiro, toalete, arrumar-se e tarefas de autocuidados (Hsu et al., 2020; Sigler et al., 2016; Wahab et al., 2016; Brummel et al., 2014; Pohlman et al., 2010; Zanni et al., 2010; Schweickert et al., 2009). Esses achados de atuaçóes do terapeuta ocupacional na UTI também estão presentes no estudo de Weinreich et al. (2017), que, além de designar o treinamento de AVDs ao terapeuta ocupacional, estima ao profissional na UTI o trabalho com tarefas funcionais, baseadas em AIVDs (Weinreich et al., 2017).

Essa notação encontrada de uso das AVDs e de tarefas funcionais significativas na UTI não são atuaçôes recentes descritas na literatura especializada e datam de, pelo menos, três décadas (Affleck et al., 1986). Todavia, entre os artigos incluídos na presente proposta, apenas uma publicação faz referência direta às AVDs/AIVDs (Brummel et al., 2014), o que representa uma lacuna a ser explorada pelos pesquisadores e profissionais. Sobre isso, Hsu et al. (2020) apresentam possibilidades trabalhadas nos estudos desse grupo, como a: elaboração de cronograma (de tarefas), leitura e escrita - sem, no entanto, classificar essas tarefas como AIVDs.

Desta forma, os achados até aqui expostos corroboram a literatura e evidenciam a participação do terapeuta ocupacional na UTI, principalmente, por atuaçóes relacionadas à 
reabilitação/mobilização precoce; isso ocorre por meio de atribuições privativas do escopo da terapia ocupacional, em particular: AVDs, AIVDs e demais tarefas funcionais (Hsu et al., 2020; Wahab et al., 2016; Fields et al., 2015; Brummel et al., 2014). Acredita-se que essa forma de intervenção é reforçada pela recorrente parceria com a Fisioterapia durante a(o): mudanças de decúbito, sentar-se no leito, ficar em pé, sentar-se em uma cadeira e andar (Yataco et al., 2019; Corcoran et al., 2017; Jolley et al., 2017; Sigler et al., 2016; Jolley et al., 2015; Witcher et al., 2015; Davis et al., 2013; Titsworth et al., 2012; Needham et al., 2010; Pohlman et al., 2010; Zanni et al., 2010; Schweickert et al., 2009). Importante ressaltar que esses achados náo representam em si o escopo de atuação possível do terapeuta ocupacional; eles refletem apenas uma forma de intervenção em resposta à dinâmica da UTI e das necessidades que os pacientes manifestam, como: fraqueza, dor, mobilidade reduzida, limitaçáo no autocuidado, banho e higiene (Okuma et al., 2017). Esses dados extraídos da literatura sugerem que há uma demanda considerável de cuidados físicos/ funcionais na UTI.

Complementarmente, a caracterização dos desfechos das publicações aqui revisadas demonstra que as açóes dos terapeutas ocupacionais trazem benefícios ao paciente grave, entre os quais estão a: recuperação física, recuperação funcional, independência nas AVDs e melhora na qualidade de vida (Hsu et al., 2020; Wahab et al., 2016; Fields et al., 2015; Brummel et al., 2014). Esses pontos corroboram a literatura e recebem complementos com outros benefícios citados em estudos não incluídos, como: ganho de força muscular, recuperação funcional, menor tempo de internação hospitalar e de permanência na UTI (Aquim et al., 2019; Weinreich et al., 2017).

Os resultados relatados evidenciam que a reabilitação e mobilização precoce, conduzida por terapeutas ocupacionais na UTI, em parceria ou não com outros profissionais, também debatidas em outros estudos (Aquim et al., 2019; Costigan et al., 2019; Weinreich et al., 2017), previnem ou reduzem os efeitos deletérios da Síndrome Pós-Cuidados Intensivos (PICS) (Corcoran et al., 2017; Wahab et al., 2016; Davis et al., 2013; Needham et al., 2010; Titsworth et al., 2012). Essa conclusão é condizente com as publicações aqui revisadas, e ainda reforça que o trabalho multidisciplinar é o mais usual e alcança os melhores resultados no manejo do paciente na UTI (Hsu et al., 2020; Jolley et al., 2017; Rawal et al., 2017; Wahab et al., 2016; Jolley et al., 2015; Davis et al., 2013; Needham et al., 2010).

Pela versatilidade, além de AVDs e AIVDs, outra forma identificada de atuação do terapeuta ocupacional na UTI foi o uso de dispositivos de comunicação alternativa (Hsu et al., 2020). Os aparatos de comunicação aumentada ou alternativa na UTI servem como instrumentos ímpares para oportunizar o envolvimento do paciente grave, sobre ventilação mecânica ou não, nos cuidados dispensados pela equipe (Zaga et al., 2019). Inicialmente, a comunicação com o paciente pode ocorrer em manifestação binária (sim ou não) sobre necessidades básicas, como: dor, (des)conforto, ambientação e necessidade de aspiração (Duffy et al., 2018). A participação do terapeuta ocupacional, na confecção, treino e uso da comunicação alternativa na UTI tem amparo na literatura e representa mais um campo de atuação especializado da profissão com o paciente grave (Costigan et al., 2019; Duffy et al., 2018; Koester et al., 2018; Brasil, 2006).

Os resultados apurados sobre os parâmetros de indicação e de contraindicação, para o início das sessóes com o terapeuta ocupacional, destacam a relevância da observação, principalmente, das contraindicaçóes (Hsu et al., 2020; Yataco et al., 2019; Deluzio et al., 2018; Corcoran et al., 2017; Wahab et al., 2016; Fields et al., 2015; Davis et al., 2013; Titsworth et al., 2012; Pohlman et al., 2010; Schweickert et al., 2009). Os critérios 
destacados nesse estudo são corroborados por publicações anteriores, cujo entendimento não é protelar os serviços da equipe de reabilitação, mas o provimento de segurança e a redução de riscos de eventos adversos no manejo do paciente na UTI, sob ventilação mecânica, no leito ou fora dele (Aquim et al., 2019; Miranda Rocha et al., 2017; Hodgson et al., 2014).

Uma vez iniciada a intervenção, a continuidade ou a suspensão da sessão, depende de sinais (físicos, mentais ou vitais) do paciente ou da ocorrência de eventos adversos (Hsu et al., 2020; Yataco et al., 2019; Deluzio et al., 2018; Wahab et al., 2016; Fields et al., 2015; Davis et al., 2013; Titsworth et al., 2012; Pohlman et al., 2010; Zanni et al., 2010; Schweickert et al., 2009). O monitoramento e o emprego desses parâmetros estão condizentes com a literatura que, além de servir para determinar o início ou o fim da sessão, aqui é entendida como uma responsabilidade solidária da equipe multidisciplinar da UTI (Aquim et al., 2019; Ratcliffe \& Williams, 2019).

Assim, a avaliação da equipe multidisciplinar da UTI pelo início das sessões com o terapeuta ocupacional, na maioria dos estudos analisados, inicia nas primeiras $24 \mathrm{~h}$ (Wahab et al., 2016; Brummel et al., 2014; Witcher et al., 2015; Zanni et al., 2010) ou, em até, 48h (Hsu et al., 2020; Davis et al., 2013; Jolley et al., 2017). Esse tempo médio está condizente com a literatura, que ressalta os benefícios da terapia ocupacional quando iniciada em até 1,5 dias (Hashem et al., 2016).

O presente estudo apresenta limitações compatíveis com manifestações em publicaçôes equivalentes. Primeiro, a busca dos artigos foi realizada em apenas quatro bases de dados científicos para selecionar artigos editados integralmente em inglês (Costigan et al., 2019; Zaga et al., 2019; Weinreich et al., 2017). Esse procedimento pode ter deixado fora das buscas publicaçóes relevantes para a área da terapia ocupacional em atuaçáo na UTI náo indexadas ou publicadas em outra língua nativa, que não fosse a inglesa.

Segundo, das 17 publicaçóes revisadas, 12 artigos tratam das atuações do terapeuta ocupacional na UTI em meio à equipe multidisciplinar ou de reabilitação, nos quais as atribuições privativas da profissão não foram discriminadas (Costigan et al., 2019). As cinco outras publicaçóes que diferenciam as práticas privativas do terapeuta ocupacional não as apresentam em detalhes.

Terceiro, uma dessas cinco publicaçóes abordou uma prática não usual por terapeutas ocupacionais brasileiros, envolvendo o Cicloergômetro, sugerindo possíveis particularidades transculturais em atribuições privativas da profissão ou, no mínimo, interesses diferentes de pesquisa (World Federation of Occupational Therapists, 2017).

Por fim, a quarta limitação se refere à PICS, reconhecida como um conjunto de sinais e sintomas aglutinados em manifestaçóes físicas (fraqueza muscular adquirida da UTI); mentais (ansiedade, depressão); cognitivas (deficit de atenção e de memória); prejuízo ao autocuidado; e redução da qualidade de vida (Held \& Moss, 2019; Daniels et al., 2018). Pelos critérios empregados nesta revisão sistemática, intencionalmente, as atuaçóes selecionadas de terapeutas ocupacionais na UTI atendem às demandas físicas, nesse primeiro momento.

Contudo, entre as publicações não incluídas, há relatos de atuação do terapeuta ocupacional no contexto de UTI sobre outros aspectos da PICS, como: ansiedade (Provancha-Romeo et al., 2019), delírium/confusão mental (Álvarez et al., 2017) e qualidade de vida (Daniels et al., 2018) - que carecem de exploração subsequente. Se fossem incluídos, esses achados aumentariam o leque de práticas do terapeuta ocupacional com pacientes graves na UTI aqui demonstrados. 


\section{Conclusáo}

O presente estudo destaca que as atuações mais realizadas por terapeutas ocupacionais na UTI envolvem intervençôes de reabilitação/mobilização precoce, seguida de atribuiçóes privativas da profissão. Conclui-se que, apesar dos achados apresentados, a atuaçáo do profissional nessa área hospitalar ainda está em construção, principalmente, pela quantidade de referenciais que não discriminam claramente a atuação do profissional na UTI. Assim, aqui são ofertadas sugestôes plausíveis, dentro da vertente da reabilitação física, de intervençôes demandadas pelo paciente crítico e sob a égide do imediatismo, produtividade e resultados requeridos aos membros da equipe dessa especialidade hospitalar. Tal como exposto, o texto pode servir de guia ao terapeuta ocupacional atuante na UTI que precisa de mais informação ou um instrumento para instigar a busca de novas práticas mediadas pela pesquisa especializada. Isso inclui estudos sobre outros efeitos prejudiciais da internação prolongada na UTI, como: delirium e prejuízos cognitivos, mentais e à qualidade de vida.

\section{Referências}

Affleck, A. T., Lieberman, S., Polon, J., \& Rohrkemper, K. (1986). Providing occupational therapy in an intensive care unit. The American Journal of Occupational Therapy, 40(5), 323-332. http://dx.doi.org/10.5014/ajot.40.5.323.

Álvarez, E. A., Garrido, M. A., Tobar, E. A., Prieto, S. A., Vergara, S. O., Briceño, C. D., \& González, F. J. (2017). Occupational therapy for delirium management in elderly patients without mechanical ventilation in an intensive care unit: a pilot randomized clinical trial. Journal of Critical Care, 37, 85-90. http://dx.doi.org/10.1016/j.jcrc.2016.09.002.

Aquim, E. E., Bernardo, W. M., Buzzini, R. F., Azeredo, N. S. G., Cunha, L. S., Damasceno, M. C. P., Deucher, R. A. O., Duarte, A. C. M., Librelato, J. T., Melo-Silva, C. A., Nemer, S. N., Silva, S. D. F., \& Verona, C. (2019). Brazilian guidelines for early mobilization in intensive care unit. Revista Brasileira de Terapia Intensiva, 31(4), 434443. http://dx.doi.org/10.5935/0103-507x.20190084.

Bombarda, T. B., Lanza, A. L., Santos, C. A. V., \& Joaquim, R. H. V. T. (2016). Terapia Ocupacional na Unidade de Terapia Intensiva (UTI) adulto e as percepçóes da equipe. Cadernos de Terapia Ocupacional da UFSCar, 24(4), 827-835. http://dx.doi.org/10.4322/0104-4931.ctoRE0861.

Brasil. Conselho Federal de Fisioterapia e Terapia Ocupacional - COFFITO. (2006). Resoluçáo no 316, de 19 de junho de 2006. Dispóe sobre a prática de atividades de vida diária, de atividades instrumentais da vida diária e tecnologia assistiva pelo terapeuta ocupacional e dá outras providências. Diário Oficial [da] República Federativa do Brasil, Brasilia, seção 1, p. 79. Recuperado em 27 de março de 2020, de https://www.coffito.gov.br/nsite/?p=3074

Brasil. (2010, 24 de fevereiro). Resoluçâo $\mathrm{n}^{\circ} 7$ de 24 de fevereiro de 2010. Dispóe sobre os requisitos mínimos para funcionamento de unidades de terapia intensiva e dá outras providências. Diário Oficial [da] República Federativa do Brasil, Brasília. Recuperado em 17 de abril de 2020, de https://bvsms.saude.gov.br/bvs/saudelegis/anvisa/2010/res0007_24_02_2010.html\#: -text=RESOLU\%C3\%87 \%C3\%83O\%20N\%C2\%BA\%207\%2C\%20DE\%2024,o\%20inciso\%20IV\%20do\%20Art

Brummel, N. E., Girard, T. D., Ely, E. W., Pandharipande, P. P., Morandi, A., Hughes, C. G., Graves, A. J., Shintani, A., Murphy, E., Work, B., Pun, B. T., Boehm, L., Gill, T. M., Dittus, R. S., \& Jackson, J. C. (2014). Feasibility and safety of early combined cognitive and physical therapy for critically ill medical and surgical patients: the Activity and Cognitive Therapy in ICU (ACT-ICU) trial. Randomized Controlled Trial, 40(3), 370379. http://dx.doi.org/10.1007/s00134-013-3136-0.

Carvalho, A. P. V., Silva, V., \& Grande, A. J. (2013). Avaliação do risco de viés de ensaios clínicos randomizados pela ferramenta da colaboração Cochrane. Diagnóstico e Tratamento, 18(1), 38-44.

Corcoran, J. R., Herbsman, J. M., Bushnik, T., Van Lew, S., Stolfi, A., Parkin, K., McKenzie, A., Hall, G. W., Joseph, W., Whiteson, J., \& Flanagan, S. R. (2017). Early rehabilitation in the medical and surgical intensive care units 
for patients with and without mechanical ventilation: an interprofessional performance improvement project. $P M$ \& $R, 9(2), 113-119$. http://dx.doi.org/10.1016/j.pmrj.2016.06.015.

Costigan, F. A., Duffett, M., Harris, J. E., Baptiste, S., \& Kho, M. E. (2019). Occupational Therapy in the ICU: a scoping review of 221 documents. Critical Care Medicine, 47(12), e1014-e1021. http://dx.doi.org/10.1097/CCM.0000000000003999.

Daniels, L. M., Johnson, A. B., Cornelius, P. J., Bowron, C., Lehnertz, A., Moore, M., Shen, Y., Schulte, P. J., Pendegraft, R. S., Hall, K. R., \& Bauer, P. R. (2018). Improving quality of life in patients at risk for post-intensive care syndrome. Mayo Clinic Proceedings. Innovations, Quality \& Outcomes, 2(4), 359-369. http://dx.doi.org/10.1016/j.mayocpiqo.2018.10.001.

Davis, J., Crawford, K., Wierman, H., Osgood, W., Cavanaugh, J., Smith, K. A., Mette, S., \& Orff, S. (2013). Mobilization of ventilated older adults. Journal of Geriatric Physical Therapy, 36(4), 162-168. http://dx.doi.org/10.1519/JPT.0b013e31828836e7.

Deluzio, S., Vora, I., Kumble, S., Zink, E. K., Stevens, R. D., \& Bahouth, M. N. (2018). Feasibility of early, motorassisted cycle ergometry in critically Ill neurological patients with upper limb weakness and variable cognitive status: a case series. American Journal of Physical Medicine \& Rehabilitation, 97(5), e37-e41. http://dx.doi.org/10.1097/PHM.0000000000000857.

Dinglas, V. D., Colantuoni, E., Ciesla, N., Mendez-Tellez, P. A., Shanholtz, C., \& Needham, D. M. (2013). Occupational therapy for patients with acute lung injury: factors associated with time to first intervention in the intensive care unit. The American Journal of Occupational Therapy, 67(3), 355-362. http://dx.doi.org/10.5014/ajot.2013.007807.

Duffy, E. I., Garry, J., Talbot, L., Pasternak, D., Flinn, A., Minardi, C., Dookram, M., Grant, K., Fitzgerald, D., Rubano, J., Vosswinkel, J., \& Jawa, R. S. (2018). A pilot study assessing the spiritual, emotional, physical/environmental, and physiological needs of mechanically ventilated surgical intensive care unit patients via eye tracking devices, head nodding, and communication boards. Trauma Surgery \& Acute Care Open, 3(1), e000180. http://dx.doi.org/10.1136/tsaco-2018-000180.

Fields, C., Trotsky, A., Fernandez, N., \& Smith, B. A. (2015). Mobility and ambulation for patients with pulmonary artery catheters: a retrospective descriptive study. Journal of Acute Care Physical Therapy, 6(2), 64-70. http://dx.doi.org/10.1097/JAT.0000000000000012.

Gurudatt, C. (2011). Sedation in Intensive Care Unit patients: assessment and awareness. Indian Journal of Anaesthesia, 55(6), 553-555. http://dx.doi.org/10.4103/0019-5049.90607.

Hashem, M. D., Nelliot, A., \& Needham, D. M. (2016). Early mobilization and rehabilitation in the ICU: moving back to the future. Respiratory Care, 61(7), 971-979. http://dx.doi.org/10.4187/respcare.04741.

Held, N., \& Moss, M. (2019). Optimizing post-intensive care unit rehabilitation. Turkish Thoracic Journal, 20(2), 147-152. http://dx.doi.org/10.5152/TurkThoracJ.2018.18172.

Higgins, J. P. T., Thomas, J., Chandler, J., Cumpston, M., Li, T., Page, M. J., \& Welch, V. A. (2019a). Cochrane Handbook for Systematic Reviews of Interventions. Nova Jersey: Wiley-Blackwell.

Higgins, S. D., Erdogan, M., Coles, S. J., \& Green, R. S. (2019b). Early mobilization of trauma patients admitted to intensive care units: a systematic review and meta-analyses. Injury, 50(11), 1809-1815. http://dx.doi.org/10.1016/j.injury.2019.09.007.

Hodgson, C. L., Stiller, K., Needham, D. M., Tipping, C. J., Harrold, M., Baldwin, C. E., Bradley, S., Berney, S., Caruana, L. R., Elliott, D., Green, M., Haines, K., Higgins, A. M., Kaukonen, K. M., Leditschke, I. A., Nickels, M. R., Paratz, J., Patman, S., Skinner, E. H., Young, P. J., \& Webb, S. A. (2014). Expert consensus and recommendations on safety criteria for active mobilization of mechanically ventilated critically ill adults. Critical Care, 18(6), 1-9. http://dx.doi.org/10.1186/s13054-014-0658-y.

Hsu, S. H., Campbell, C., Weeks, A. K., Herklotz, M., Kostelecky, N., Pastores, S. M., Halpern, N. A., \& Voigt, L. P. (2020). A pilot survey of ventilated cancer patients' perspectives and recollections of early mobility in the intensive care unit. Supportive Care in Cancer, 28(2), 747-753. http://dx.doi.org/10.1007/s00520-019-04867-1.

Jolley, S. E., Dale, C. R., \& Hough, C. L. (2015). Hospital-level factors associated with report of physical activity in patients on mechanical ventilation across Washington State. Annals of the American Thoracic Society, 12(2), 209215. http://dx.doi.org/10.1513/AnnalsATS.201410-480OC. 
Jolley, S. E., Moss, M., Needham, D. M., Caldwell, E., Morris, P. E., Miller, R. R., Ringwood, N., Anders, M., Koo, K. K., Gundel, S. E., Parry, S. M., \& Hough, C. L., \& Acute Respiratory Distress Syndrome Network Investigators. (2017). Point Prevalence study of mobilization practices for acute respiratory failure patients in the United States. Critical Care Medicine, 45(2), 205-215. http://dx.doi.org/10.1097/CCM.0000000000002058.

Koester, K., Troeller, H., Panter, S., Winter, E., \& Patel, J. J. (2018). Overview of intensive care unit-related physical and functional impairments and rehabilitation-related devices. Nutrition in Clinical Practice, 33(2), 177-184. http://dx.doi.org/10.1002/ncp.10077.

Koukourikos, K., Tsaloglidou, A., \& Kourkouta, L. (2014). Muscle atrophy in intensive care unit patients. Acta Informatica Medica, 22(6), 406-410. http://dx.doi.org/10.5455/aim.2014.22.406-410.

Miot, H. A. (2016). Análise de concordância em estudos clínicos e experimentais. Jornal Vascular Brasileiro, 15(2), 8992. http://dx.doi.org/10.1590/1677-5449.004216.

Miranda Rocha, A. R., Martinez, B. P., Maldaner da Silva, V. Z., \& Forgiarini Junior, L. A. (2017). Early mobilization: why, what for and how? Medicina Intensiva, 41(7), 429-436. http://dx.doi.org/10.1016/j.medin.2016.10.003.

Moher, D., Shamseer, L., Clarke, M., Ghersi, D., Liberati, A., Petticrew, M., Shekelle, P., Stewart, L. A., \& PRISMAP Group. (2015). Preferred reporting items for systematic review and meta-analysis protocols (PRISMA-P) 2015 statement. Systematic Reviews, 4(1), 1. http://dx.doi.org/10.1186/2046-4053-4-1.

Needham, D. M., Korupolu, R., Zanni, J. M., Pradhan, P., Colantuoni, E., Palmer, J. B., Brower, R. G., \& Fan, E. (2010). Early physical medicine and rehabilitation for patients with acute respiratory failure: a quality improvement project. Archives of Physical Medicine and Rehabilitation, 91(4), 536-542. http://dx.doi.org/10.1016/j.apmr.2010.01.002.

Ohura, T., Hase, K., Nakajima, Y., \& Nakayama, T. (2017). Validity and reliability of a performance evaluation tool based on the modified Barthel Index for stroke patients. BMC Medical Research Methodology, 17(1), 131. http://dx.doi.org/10.1186/s12874-017-0409-2.

Okuma, S. M., Paula, A., Carmo, G. P., \& Pandolfi, M. (2017). Caracterização dos pacientes atendidos pela terapia ocupacional em uma unidade de terapia intensiva adulto. REVISBRATO, 1(5), 574-588. http://dx.doi.org/10.47222/2526-3544.RBTO8311.

Paz, I. A., Fréz, A. R., Schiessl, L., Ribeiro, L. G., Preis, C., \& Guérios, L. (2016). Terapia complexa descongestiva no tratamento intensivo do linfedema: revisão sistemática. Fisioterapia e Pesquisa, 23(3), 311-317. http://dx.doi.org/10.1590/1809-2950/15002623032016.

Pohlman, M. C., Schweickert, W. D., Pohlman, A. S., Nigos, C., Pawlik, A. J., Esbrook, C. L., Spears, L., Miller, M., Franczyk, M., Deprizio, D., Schmidt, G. A., Bowman, A., Barr, R., McCallister, K., Hall, J. B., \& Kress, J. P. (2010). Feasibility of physical and occupational therapy beginning from initiation of mechanical ventilation. Critical Care Medicine, 38(11), 2089-2094. http://dx.doi.org/10.1097/CCM.0b013e3181f270c3.

Provancha-Romeo, A. F., Hoffman, A. L., Malcolm, M. P., Coatsworth, J. D., Laxton, L. R., Freeman, K. M., \& Schmid, A. A. (2019). Mind-body interventions utilized by an occupational therapist in a medical intensive care unit: an exploratory case study. Work, 63(2), 191-197. http://dx.doi.org/10.3233/WOR-192920.

Ratcliffe, J., \& Williams, B. (2019). Impact of a mobility team on intensive care unit patient outcomes. Critical Care Nursing Clinics of North America, 31(2), 141-151. http://dx.doi.org/10.1016/j.cnc.2019.02.002.

Rawal, G., Yadav, S., \& Kumar, R. (2017). Post-intensive care syndrome: an overview. Journal of Translational Internal Medicine, 5(2), 90-92. http://dx.doi.org/10.1515/jtim-2016-0016.

Schweickert, W. D., Pohlman, M. C., Pohlman, A. S., Nigos, C., Pawlik, A. J., Esbrook, C. L., Spears, L., Miller, M., Franczyk, M., Deprizio, D., Schmidt, G. A., Bowman, A., Barr, R., McCallister, K. E., Hall, J. B., \& Kress, J. P. (2009). Early physical and occupational therapy in mechanically ventilated, critically ill patients: a randomised controlled trial. Lancet, 373(9678), 1874-1882. http://dx.doi.org/10.1016/S0140-6736(09)60658-9.

Shiwa, S. R., Costa, L. O. P., Moser, A. D. L., Aguiar, I. C., \& Oliveira, L. V. F. (2011). PEDro: a base de dados de evidências em fisioterapia. Fisioterapia em Movimento, 24(3), 523-533. http://dx.doi.org/10.1590/S010351502011000300017. 
Sigler, M., Nugent, K., Alalawi, R., Selvan, K., Tseng, J., Edriss, H., Turner, A., Valdez, K., \& Krause, D. (2016). Making of a successful early mobilization program for a medical intensive care unit. Southern Medical Journal, 109(6), 342-345. http://dx.doi.org/10.14423/SMJ.0000000000000472.

Thomas, E. M., Rybski, M. F., Apke, T. L., Kegelmeyer, D. A., \& Kloos, A. D. (2017). An acute interprofessional simulation experience for occupational and physical therapy students: key findings from a survey study. Journal of Interprofessional Care, 31(3), 317-324. http://dx.doi.org/10.1080/13561820.2017.1280006.

Titsworth, W. L., Hester, J., Correia, T., Reed, R., Guin, P., Archibald, L., Layon, A. J., \& Mocco, J. (2012). The effect of increased mobility on morbidity in the neurointensive care unit. Journal of Neurosurgery, 116(6), 13791388. http://dx.doi.org/10.3171/2012.2.JNS111881.

Wahab, R., Yip, N. H., Chandra, S., Nguyen, M., Pavlovich, K. H., Benson, T., Vilotijevic, D., Rodier, D. M., Patel, K. R., Rychcik, P., Perez-Mir, E., Boyle, S. M., Berlin, D., Needham, D. M., \& Brodie, D. (2016). The implementation of an early rehabilitation program is associated with reduced length of stay: A multi-ICU study. The Journal of the Intensive Care Society, 17(1), 2-11. http://dx.doi.org/10.1177/1751143715605118.

Weinreich, M., Herman, J., Dickason, S., \& Mayo, H. (2017). Occupational therapy in the intensive care unit: a systematic review. Occupational Therapy in Health Care, 31(3), 205-213. http://dx.doi.org/10.1080/07380577.2017.1340690.

Wieske, L., Dettling-Ihnenfeldt, D. S., Verhamme, C., Nollet, F., van Schaik, I. N., Schultz, M. J., Horn, J., \& van der Schaaf, M. (2015). Impact of ICU-acquired weakness on post-ICU physical functioning: a follow-up study. Critical Care, 19(1), 196. http://dx.doi.org/10.1186/s13054-015-0937-2.

Witcher, R., Stoerger, L., Dzierba, A. L., Silverstein, A., Rosengart, A., Brodie, D., \& Berger, K. (2015). Effect of early mobilization on sedation practices in the neurosciences intensive care unit: a preimplementation and postimplementation evaluation. Journal of Critical Care, 30(2), 344-347. http://dx.doi.org/10.1016/j.jcrc.2014.12.003.

World Federation of Occupational Therapists, Mackenzie, L., Coppola, S., Alvarez, L., Cibule, L., Maltsev, S., Loh, S. Y., Mlambo, T., Ikiugu, M. N., Pihlar, Z., Sriphetcharawut, S., Baptiste, S., \& Ledgerd, R. (2017). International occupational therapy research priorities. OTJR, 37(2), 72-81. http://dx.doi.org/10.1177/1539449216687528.

Wu, J., Vratsistas-Curto, A., Shiner, C. T., Faux, S. G., Harris, I., \& Poulos, C. J. (2019). Can in-reach multidisciplinary rehabilitation in the acute ward improve outcomes for critical care survivors? A pilot randomized controlled trial. Journal of Rehabilitation Medicine, 51(8), 598-606. http://dx.doi.org/10.2340/16501977-2579.

Yataco, R. A., Arnold, S. M., Brown, S. M., David Freeman, W., Carmen Cononie, C., Heckman, M. G., Partridge, L. W., Stucky, C. M., Mellon, L. N., Birst, J. L., Daron, K. L., Zapata-Cooper, M. H., \& Schudlich, D. M. (2019). Early progressive mobilization of patients with external ventricular drains: safety and feasibility. Neurocritical Care, 30(2), 414-420. http://dx.doi.org/10.1007/s12028-018-0632-7.

Zaga, C. J., Berney, S., \& Vogel, A. P. (2019). The feasibility, utility, and safety of communication interventions with mechanically ventilated intensive care unit patients: a systematic review. American Journal of Speech-Language Pathology, 28(3), 1335-1355. http://dx.doi.org/10.1044/2019_AJSLP-19-0001.

Zago, M., Capodaglio, P., Ferrario, C., Tarabini, M., \& Galli, M. (2018). Whole-body vibration training in obese subjects: a systematic review. PLoS One, 13(9), e0202866. http://dx.doi.org/10.1371/journal.pone.0202866.

Zanni, J. M., Korupolu, R., Fan, E., Pradhan, P., Janjua, K., Palmer, J. B., Brower, R. G., \& Needham, D. M. (2010). Rehabilitation therapy and outcomes in acute respiratory failure: an observational pilot project. Journal of Critical Care, 25(2), 254-262. http://dx.doi.org/10.1016/j.jcrc.2009.10.010. 


\section{Contribuição dos Autores}

Estéfanny da Silva Bittencourt e Paula Silva Moreira: Fizeram a identificação dos artigos, análise dos artigos incluídos, tabulação dos dados, concepção do texto e redação textual. Glenda Miranda da Paixão e Marcelo Marques Cardoso: concepção do texto, análise e revisão dos dados, orientação do estudo e redação textual. Todos os autores aprovaram a versão final do artigo.

\section{Fonte de Financiamento}

Faculdade de Fisioterapia e Terapia Ocupacional, Instituto de Ciências da Saúde - Universidade Federal do Pará (FFTO, ICS - UFPA).

\section{Autor para correspondência}

Marcelo Marques Cardoso

e-mail: marcelomc@ufpa.br

\section{Editora de seçáo}

Profa. Dra. Iza Faria-Fortini 